\title{
Endodontic treatment during the COVID-19 pandemic - perception and behaviour of dental professionals
}

\author{
Fabio de A. Gomes ${ }^{2}$, Eduarda C. Malhão², Cláudio Maniglia-Ferreira' , Danilo L. F. Lima' , \\ Maísa Casarin², Fernanda G. Pappen² \\ 1. Universidade de Fortaleza, Faculdade de Odontologia, Departamento de Endodontia Fortaleza, Brasil \\ 2. Universidade Federal de Pelotas, Faculdade de Odontologia, Programa de Pós Graduação em Odontologia, Pelotas, \\ Brasil
}

\begin{abstract}
This study evaluated the impact of COVID-19 on the endodontic treatment routine. It was a cross-sectional study using an online questionnaire applied to endodontists to collect information about practical modifications during endodontic treatment to protect professionals and patients against the COVID-19 outbreak. A total 1105 participants from Brazil participated in the survey. More than $90 \%$ of respondents identify the high risk of COVID-19 infection to dentists and the need to change some clinical practices. Most respondents (60.1\%) are partially following social isolation. The need for a change in Personal Protective Equipment (PPE) during dental appointments was mentioned by $97.1 \%$ of respondents. The use of minimal adequate PPE during the pandemic period was associated with the area of residence and marital status of
\end{abstract}

participants. Only 30\% of respondents say they use the minimal adequate PPE. Most respondents will change cavity access preparation to reduce virus dissemination. Other changes in endodontic appointments were described in the survey: greater attention to biosafety measures, duration of dental appointments, and duration of intervals between appointments. Endodontists still need to identify the best arrangement for performing their procedures safely during the COVID-19 pandemic. Specific guidelines require detailed information for each specialty and its procedures. Received: November 2020; Accepted: February 2021.

Keywords: biosafety - coronavirus - dentistry - endodontics SARS-CoV-2.

\section{Tratamento endodôntico durante a pandemia de COVID-19 - Percepção e comportamento dos profissionais de odontologia}

\begin{abstract}
RESUMO
Este estudo transversal foi realizado por meio de um questionário online. $O$ questionário foi aplicado a endodontistas e coletou informações sobre modificações práticas durante o tratamento endodôntico para combater o surto de COVID-19 e proteger profissionais e pacientes. Um total de 1105 participantes do Brasil participaram da pesquisa. Mais de $90 \%$ dos entrevistados identificam o alto risco de infecção por COVID-19 para os dentistas e a necessidade de mudar algumas práticas clínicas. A maioria dos entrevistados $(60,1 \%)$ segue parcialmente o isolamento social. A necessidade de mudanças dos Equipamentos de Proteção Individual (EPIs) durante as consultas odontológicas foi referida por 97,1\% dos entrevistados. $O$ uso de EPIs mínimos adequados durante o período pandêmico foi associado à área de residência e ao
\end{abstract}

estado civil dos participantes. Apenas 30\% dos participantes afirmou usar os EPIs mínimos durante a pandemia. A maioria dos entrevistados mudará a preparação do acesso à cavidade para reduzir a disseminação do vírus. Outras mudanças nas consultas endodônticas foram descritas na pesquisa: maior atenção às medidas de biossegurança, duração das consultas odontológicas e intervalos entre as consultas. Os endodontistas ainda precisam distinguir a melhor maneira para realizar seus procedimentos com segurança, durante a pandemia de COVID-19. Diretrizes especificas requerem informações detalhadas para cada especialidade e seus procedimentos.

Palavras-chave: biossegurança - coronavirus - odontologiaendodontia - SARS-CoV-2. 


\section{INTRODUCTION}

Coronavirus disease (COVID-19) has emerged as the largest global pandemic and has already affected several countries, including Brazil ${ }^{1}$. Even though the disease sometimes appears as an asymptomatic or symptomatic clinical condition ${ }^{2}$, the diagnosis is most commonly associated with fever, dry cough, fatigue and difficulty in breathing ${ }^{3}$. COVID-19 can progress to other serious conditions with severe respiratory symptoms, including dyspnea and pneumonia, which can lead to death ${ }^{4,5}$.

Although the mortality associated with COVID-19 is low, it has high spreading potential ${ }^{6}$ and high levels of transmissibility ${ }^{6-8}$. It spreads mainly from person to person through contact transmission, including oral, nasal and eye membrane contact; or direct transmission, including sneezing, coughing and droplet inhalation'. Droplets containing the virus can settle on surfaces, where the virus can remain viable for days, causing significant concern among healthcare professionals and support services, including dental professionals ${ }^{10}$.

Dental care settings consistently involve the risk of COVID-19 infection due to the specificity of the procedures conducted in them. Dental professionals are constantly exposed to pathogenic microorganisms, including viruses and bacteria ${ }^{11}$. The exposure to saliva and blood, the use of sharp instruments, and the droplets and aerosols generated during dental treatment can contaminate instruments and environmental surfaces in dental practice, or infect the professional directly ${ }^{12-14}$.

The American Dental Association (ADA) recently issued guidance to prevent infection in the COVID-19 pandemic during emergency and nonemergency dental procedures ${ }^{15}$. Infection control in dental practice includes the use of Personal Protective Equipment (PPE), and cleaning and disinfecting the dental care environment as part of the clinical routine needed to prevent cross-infection ${ }^{16}$.

The available information on how dentists should work during the COVID-19 pandemic is very helpful in preventing infections. However, this information refers to urgent and emergency procedures or dental procedures in general, but does not provide more specific explanations on actions required for each specialty, e.g., endodontics. Thus, the aim of this study is to evaluate, through the application of a questionnaire, the impact of COVID-19 on endodontic treatment routine among Brazilian dentists, including possible changes in the technique and/or in preventive measures.

\section{MATERIALS AND METHODS}

The institutional Research Ethics Committee approved thisstudy(CAAE:31064820.6.0000.5052). Participants who accepted to take part in the survey signed an informed consent form (ICF) online.

This was a cross-sectional study using an online questionnaire with a convenience sample. The questionnaire design, pilot study and strategies for enrolling dentists were previously discussed, and it was decided that a convenience sample enrolled using social media would be valid to acquire a large number of respondents. The questionnaire was posted on the Google Forms platform, where it was available for one week, after which it was closed.

Respondents had to be dentists who regularly performed endodontic procedures in clinical practice (there was no need to be a specialist in endodontics). The submission was considered only when the 'submit' button was clicked at the end of the questionnaire.

This study was conducted from May 2 to May 6, 2020. The questionnaire was distributed by email as well as being posted on several social media platforms, such as Facebook and WhatsApp. It comprised 20 closed-ended questions designed to collect information about practical modifications established against the COVID-19 outbreak during endodontic treatment to protect professionals and patients (Fig. 1).

The questionnaire was divided into two sections. The first section recorded personal data such as age, sex, years' experience in dental practice, area of residence, and professional setting (private or public) of dental practice. The second section included questions about dentists' perception and behavior regarding endodontic treatment during the COVID-19 pandemic. For data analysis, we considered minimal PPE before COVID-19 pandemic to be the use of gloves, surgical masks, protective eyewear, surgical caps, gowns or lab coats. During the pandemic, minimal PPE includes gloves, N95 masks, protective eyewear, surgical caps, disposable gowns or lab coats, and shoe covers. After responding to the questionnaire, respondents were requested to provide their registration number in the Regional Council of Dentistry (RCD) to prevent duplication of data. 


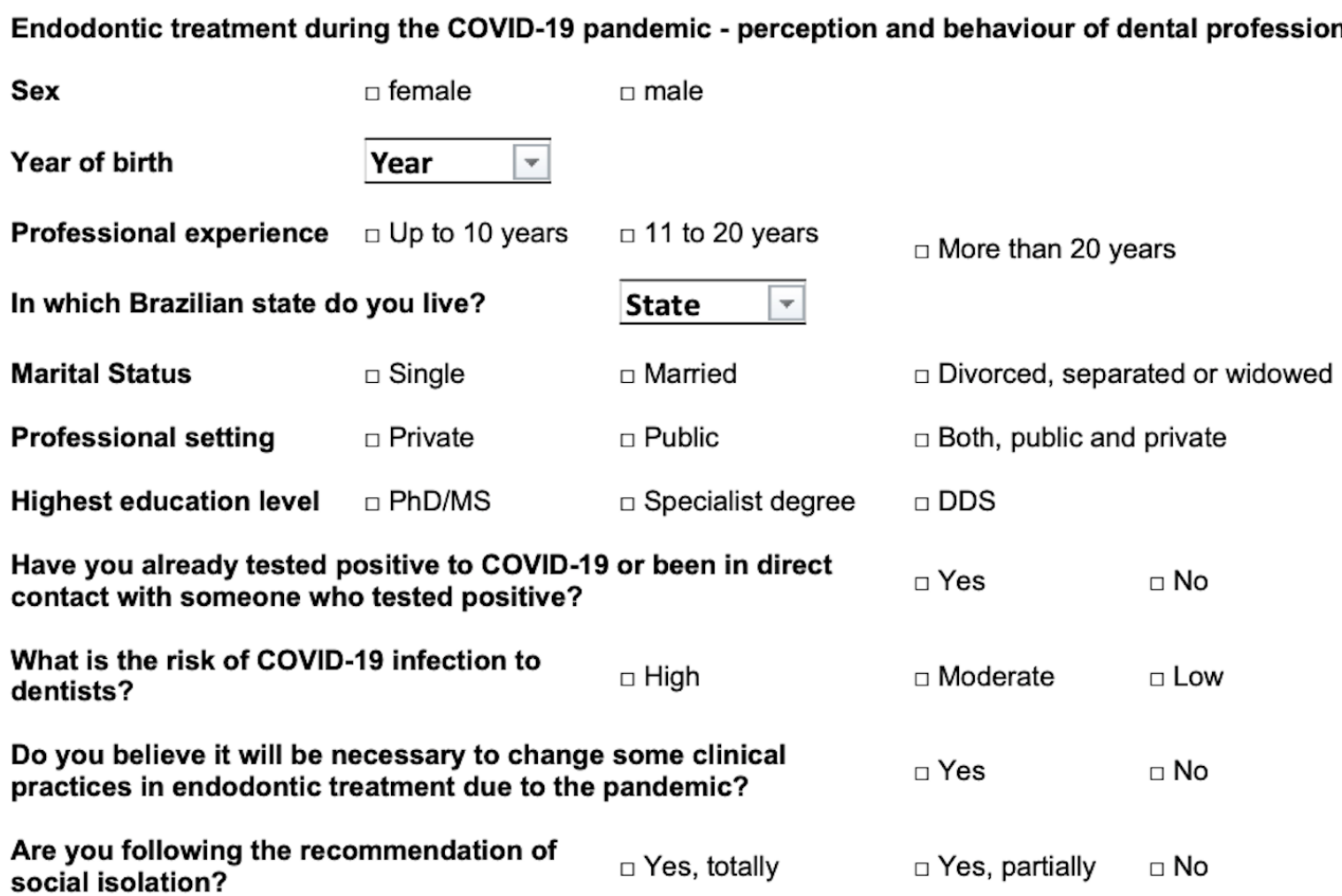

In comparison to the most affected countries, how do you expect the infection would affect our country? $\square$ Brazil would have a lower or similar number of COVID-19 infected people in comparison to the most affected countries $\checkmark$ Brazil would be one of the most affected countries in the world.

During the COVID-19 pandemic, will you change the PPEs used during dental appointments?

$\square$ Yes $\quad \square$ No

Which PPE did you usually wear before the COVID-19 pandemic?

Which PPE do you think it is necessary to wear during the pandemic?

select

Before the COVID-19 pandemic, did you perform rubber dam

isolation before or after endodontic access cavity preparation?

$\square$ Before access $\square$ After access

During the COVID-19 pandemic, do you perform rubber dam isolation before or after endodontic access cavity preparation?

$\square$ Before access $\square$ After access

Before the COVID-19 pandemic, how did you perform endodontic access cavity?

During the COVID-19 pandemic, how are you performing endodontic access cavity?

Which changes in dental practice do you consider during the COVID-19 pandemic? $\square$ Using low-speed handpiece

$\square$ Using high-speed handpiece with water cooling

$\checkmark$ Using high-speed handpiece with irrigation syringe

$\checkmark$ Using high-speed handpiece without water cooling

$\square$ Using low-speed handpiece

$\square$ Using high-speed handpiece with water cooling

$\square$ Using high-speed handpiece with irrigation syringe

$\checkmark$ Using high-speed handpiece without water cooling

\section{Changes}

Fig. 1: Questionnaire sent to Brazilian dental professionals 
Data were collected and analysed by SPSS 25.0 for Windows (IBM corp., SPSS, Inc., Chicago, IL, USA). Descriptive statistics were performed, and chi-square and Fisher's exact tests were used to test the significance of possible associations. The level of significance was $5 \%(\mathrm{p}<0.05)$.

\section{RESULTS}

A total 1105 questionnaires were answered from all of Brazil's 25 states. Mean respondent age was $37.79 \pm 10.35$ years. Female respondents accounted for $66.2 \%$ (732) and male $33.8 \%$ (373) of the total. Regarding time elapsed since graduation in dentistry, $44.2 \%$ (488) of respondents graduated in the last 10 years, $30 \%$ (332) graduated between 11 and 20 years ago, and $25.8 \%$ (285) graduated more than 20 years ago.

The percentage of respondents by regions of Brazil was $263(23.8 \%)$ from the south, $335(30.3 \%)$ from the south-east, $406(36.7 \%)$ from the north-east, 54 $(4.9 \%)$ from the mid-west and $47(4.3 \%)$ from the north. Regarding clinical practice, most respondents worked only in private practice $(72.5 \%)$, whilst $5.7 \%$ worked exclusively in public practice, and $21.8 \%$ worked in public and private practice (Table $1)$.

Ninety-seven respondents (8.8\%) had already tested positive for COVID-19 or had been in direct contact with someone who tested positive. A total $1011(91.5 \%)$ respondents identify the high risk of COVID-19 infection to dentists, while 1073 (97.1\%) recognise the need to change some clinical practices in endodontic treatment due to the pandemic.

Most respondents (60.1\%) are partially following social isolation. At the time the questionnaire was applied, $777(70.3 \%)$ of respondents believed that Brazil would have a lower or similar number of COVID-19 infected people in comparison to the most affected countries, while $328(29.7 \%)$ believed that Brazil would be one of the most severely affected countries in the world.

When asked if during the COVID-19 pandemic they would change the PPE used during dental appointments, 1073 (97.1\%) answered affirmatively. Table 2 shows the use of minimal adequate PPE before and during the pandemic period, and how it differed according to respondent background characteristics.

Fig. 2 illustrates the changes in endodontic cavity access during the pandemic. Most respondents

\section{Table 1. Respondent demographics}

n

$\%$

\section{Sex}

Female

Male

373

33.8

Professional experience

\begin{tabular}{|l|r|r|}
\hline Up to 10 years & 488 & 44.2 \\
\hline 11 to 20 years & 332 & 30.0 \\
\hline More than 20 years & 285 & 25.8 \\
\hline & & \\
\hline Area of residence & & \\
\hline South-east & 335 & 30.3 \\
\hline South & 263 & 23.8 \\
\hline North-east & 406 & 36.7 \\
\hline Mid-west & 54 & 4.9 \\
\hline North & 47 & 4.3 \\
\hline
\end{tabular}

\section{Marital status}

Single

402

36.4

Divorced, separated or widowed

6.9

Married

625

56.6

Professional setting

Private

$801 \quad 72.5$

Public

63

5.7

Both, public and private

241

21.8

Highest education level

$\mathrm{PhD} / \mathrm{MS}$

322

29.1

Specialist degree

646

58.5

DDS

137

12.4

(75.93\%) agree that the use of a rubber dam before cavity access preparation diminishes the risk of virus dissemination. Most participants $(56.83 \%)$ said that they would still use the high-speed handpiece during COVID-19 pandemic for cavity access preparation. Other changes in endodontic appointments were also considered in the survey, including greater attention to biosafety measures, duration of dental appointments, and duration of intervals between appointments (Fig. 3).

\section{DISCUSSION}

Since the beginning of the pandemic, other studies have aimed at measuring the impact of the disease on dental professionals. However, ours is the first study 
Table 2 - Association between the respondents' demographic and professional characteristics and the use of adequate PPE before and during the COVID-19 pandemic.

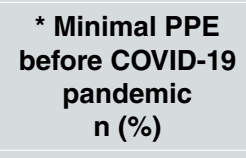

Total

Sex

Female

Male

Professional experience

Up to 10 years

11 to 20 years

More than 20 years

Area of residence

South-east

South

North-east

Mid-west

North

\section{Marital status}

Single

Divorced, separated or widowed

Married

\section{Professional practice}

Private

Public

Both, public and private

Highest education level

$\mathrm{PhD} / \mathrm{MS}$

P value

.000

170 (23.2)

$85(22.8)$

$100(20.5)$

$85(25.7)$

$70(24.7)$

$273(82.2)$

.462

** Minimal PPE

during COVID-19

$$
\mathrm{n}(\%)
$$

$255(23.1)$

$P$ value

$223(78.2)$

$266(79.4)$

$210(79.8)$

$322(79.3)$

48 (88.9)

$42(89.4)$

.247

67 (20.0)

76 (28.9)

89 (21.9)

16 (29.6)

7 (14.9)

.037

68 (16.9)

19 (24.4)

$168(26.9)$

.001

496 (79.4)

637 (79.5)

$58(92.1)$

.054

174 (21.7)

15 (23.8)

.186

$66(27.4)$

69 (21.4)

940

$272(84.5)$
$152(23.5)$

34 (24.8)

\begin{tabular}{r|r}
\hline $152(23.5)$ \\
\hline
\end{tabular}

Specialist degree

DDS caps, disposable gowns or lab coats and shoe covers.

.071

$105(76.6)$

670

to emphasize the need for changes in endodontic practice. Surveys using questionnaires are a popular method for determining the views of a sample of healthcare professionals or patients ${ }^{17}$.

Genetic and epidemiological research has found that the COVID-19 outbreak began with the transmission of the virus from animal to human, followed by the spread from human to human ${ }^{18,19}$. Further studies have demonstrated that not only is the virus transmitted by symptomatic patients, but also by asymptomatic persons or even those in the incubation phase ${ }^{18,20,21}$. This difficulty of identifying whether or not individuals have the virus makes the regulation of disease transmission extremely challenging. This has led to the constant recommendation for people to practice social isolation as much as possible during the pandemic period. However, in China, the demand for urgent dental treatment decreased by only $38 \%$ during the pandemic period ${ }^{22}$, reflecting the fact that urgent 


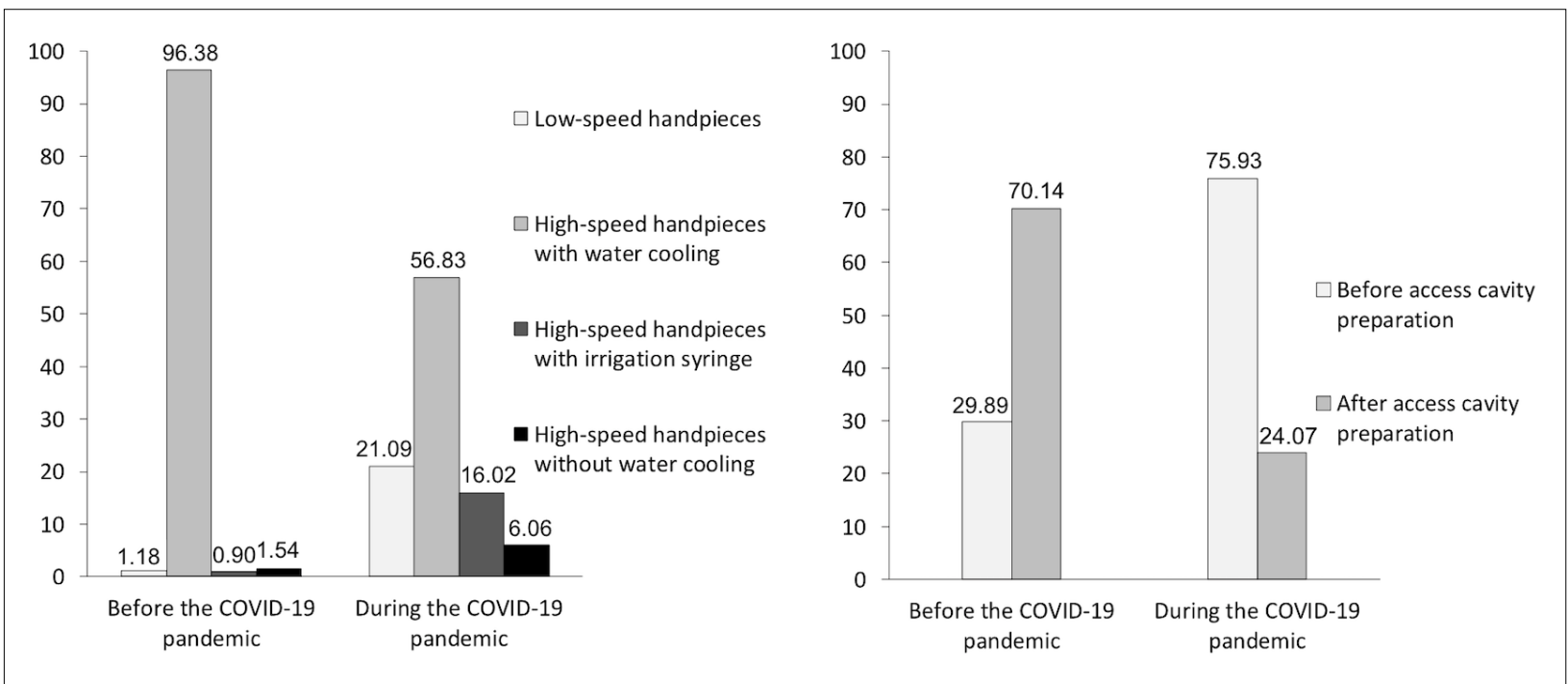

Fig. 2: Professional choices regarding cavity access preparation before and during the COVID-19 pandemic

dental services will always be essential, making it difficult for dental care providers to practice social isolation. In addition, the interruption of dental care during this period puts pressure on the emergency departments at hospitals, which are already dealing with the pandemic ${ }^{23}$.

Although at this point Brazil is an epicenter of coronavirus infection, the present study was conducted from May 2 to May 6, 2020, when Brazil only had 90,000 cases of COVID-19 and 6,000 confirmed deaths. The information from the survey showed that most dentists were not in total social isolation, and were still performing different types of procedures, although the ADA (American Dental Association) had recommended that dentists should postpone elective treatments to avoid contact, focusing only on urgent and emergency care ${ }^{24}$.

It has been suggested that dental professionals are at higher risk for COVID-19 infection than any other professional ${ }^{11}$, requiring strategies to prevent infection, including pre-exposure and post-exposure prophylaxis. The results of the present study demonstrated that dental professionals are aware of this, with most respondents (91.5\%) identifying the high risk of COVID-19 infection to dentists, and $97.1 \%$ saying they would change the PPE used during dental appointments during the pandemic. In fact, considering the severity of the COVID-19 pandemic, and in the light of the strong commitment of several dental associations, it is essential to provide simple, clear guidelines for managing dental patients and protecting dentists against risks ${ }^{25}$.
COVID-19 transmission can be expected via contact with droplets and aerosols generated during dental clinical procedures ${ }^{26}$. The guidelines recommended for dentists and dental staff by the Centers for Disease Control and Prevention (CDC), the ADA and the World Health Organization (WHO) to control the spread of COVID-19 include PPE, hand washing, detailed patient evaluation, rubber dam

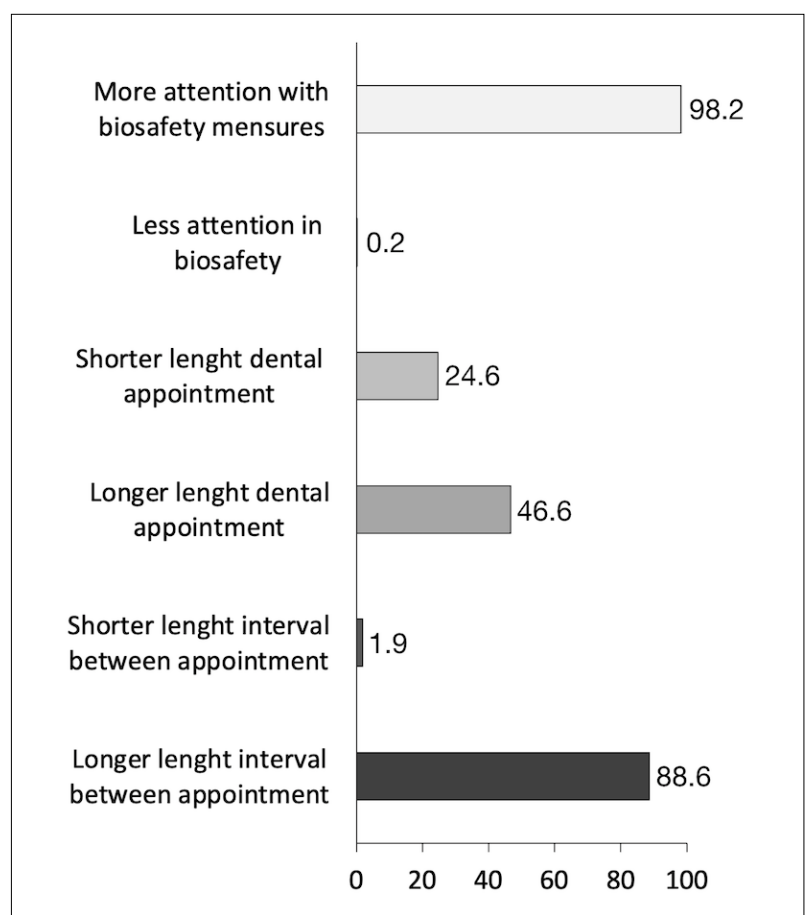

Fig. 3: Changes in endodontic dental practice during the COVID-19 pandemic according to questionnaire respondents 
isolation, mouthwash before dental procedures, and disinfection of every exposed surface ${ }^{27}$.

Our results showed that before the pandemic, more than $80 \%$ of dental professionals used adequate PPE. The use of adequate PPE was more frequent among women, reiterating the concept that women tend to be more careful. This is somehow expected, since in general, women get less sick, suffer fewer accidents and die later because they are more careful and prevent more than men do. However, this association has not been demonstrated considering the pandemic period only, because it is still too recent.

Even though more than $97 \%$ of the respondents are aware of the need to change the PPE they use during the pandemic, at the time the survey was carried out, less than $30 \%$ of respondents said they used adequate PPE. Single respondents seem to be less worried than married respondents about using appropriate PPE during the pandemic, possibly because they usually live alone and worry less about other family members to whom they could transmit the disease if they became infected. We also found that the percentage of professionals using adequate PPE is higher in the southern and central-western Brazilian regions. It is interesting to note that at the moment, these areas present the lowest number of COVID-19 infected people.

It has already been recognized that the use of highvolume saliva ejectors could reduce the production of droplets and aerosols in dental procedures, thereby protecting dentists from infection. Furthermore, face shields and protective eyewear are essential whenever high- or low-speed drilling are used. The use of rubber dam isolation reduces the generation of droplets and aerosol mixed with patient saliva and/or blood in $1 \mathrm{~m}$ diameter of the surgical field by $70 \%{ }^{28}$. Opportunely, the current study showed that $75.93 \%$ of respondents consider that rubber dam isolation before endodontic access cavity reduces the risk of virus transmission. In addition, the use of a highspeed handpiece with water-cooling to perform the access cavity was seen as a concern. Some of the respondents intend to change the technique during endodontic procedure, using low-speed handpiece or discarding the use of water-cooling. However, the use of high speed without water-cooling is not recommended, and in these cases, the damage to dental structure should also be considered.
Nearly all participants believe that biosafety in dental practice during the pandemic should receive more attention. This seems to be a consequence of extensive media coverage regarding the need to reinforce hygiene methods such as constant handwashing, use of a mask, coughing into a bent elbow, and keeping a distance, among others ${ }^{29}$. Almost half the respondents believe that longer dental appointments are one the changes that should be implemented in clinical practice during the COVID-19 pandemic. Even though there is no published data regarding the adequate length of dental appointments, it seems reasonable to believe that longer dental appointments may allow the dental professional to better complete the endodontic procedures, avoiding repeated contact with the patients on different days. Moreover, it has been recommended that the interval between dental appointments should last long enough for possible contagious droplets to stop floating in the air and settle on the surfaces for subsequent disinfection of the entire dental office and replacement of all $\mathrm{PPE}^{30}$. In the current study, almost $90 \%$ of respondents believe that the interval between dental appointments should be longer during the pandemic, which is in agreement with the recommendations.

The effects of COVID-19 are becoming worse day by day. As dentistry is at the top of professions at risk of contamination, many dentists are anxious and afraid to work. The general population, however, still demands emergency and non-emergency dental services. It is therefore essential that dentists should have appropriate guidelines for the protection of both parties. Several points can and should be analyzed regarding dental practice during the COVID-19 pandemic. Considering the high level of risk to which dentists are exposed, it is crucial that clearer and more detailed protocols should be developed so that professionals know how to act to prevent the virus from spreading. This risk can be reduced if dentists act appropriately in all specialties and when performing any type of procedure.

In conclusion, dentists who perform endodontic treatment still need to be able to identify the best arrangements for performing their procedures safely during COVID-19 pandemic. Specific guidelines require detailed information for each specialty and its procedures. 


\section{ACKNOWLEDGMENTS}

The authors would like to thank all the participants in the study.

\section{DECLARATION OF CONFLICTING INTERESTS}

The authors declared no potential conflicts of interest with respect to the research, authorship, and/or publication of this article.

\section{FUNDING:}

E. C. M.'s work is funded by Coordenacao de Aperfeicoamento de Pessoal de Nivel Superior (CAPES), Brazil.

\section{CORRESPONDENCE}

Dr. Fernanda Geraldo Pappen

Gonçalves Chaves, 457/507,

Pelotas, RS Brazil, CEP: 96015-560

ferpappen@yahoo.com.br

17. Field TS, Cadoret CA, Brown ML, Ford M et al. Surveying Physicians Do Components of the "Total Design Approach" to Optimizing Survey Response Rates Apply to Physicians? Med Care 2002;40:596-606

18. Chan JF, Yuan S, Kok KH, Wang-To KK et al. A familial cluster of pneumonia associated with the 2019 novel coronavirus indicating person-to-person transmission: a study of a family cluster. Lancet 2020;395:514-523

19. Del Rio C, Malani PN. 2019 novel coronavirus-important information for clinicians. JAMA 2020;323. doi: 10.1001/ jama.2020.1490.

20. Rothe C, Schunk M, Sothmann P, Bretzel G et al. Transmission of 2019-nCoV infection from an asymptomatic contact in Germany. N Engl J Med 2020;382:970-971

21. Ather A, Ruparel NB, Diogenes A, Hargreaves KM. Coronavirus Disease 19 (COVID-19): Implications for Clinical Dental Care. J Endod 2020;46:584-595.

22. Guo H, Zhou Y, Liu X. Tan J. The impact of the COVID-19 epidemic on the utilization of emergency dental services. J Dent Sci 2020; 15: 564-567

23. Alharbi A, Alharbi S, Alqaidi S. Guidelines for dental care provision during the COVID-19 pandemic. Saudi Dent J 2020;32:181-186

24. American Dental Association (2020). ADA recommending dentists postpone elective procedures: https://www.ada. org/en/publications/ada-news/2020-archive/march/adarecommending-dentists-postpone-elective-procedures

25. Spagnuolo G, De Vito D, Rengo S, Tatullo M. COVID-19 Outbreak: An Overview on Dentistry. Int J Environ Res Public Health 2020;17:2094 doi: 10.3390/ijerph17062094

26. Sabino-Silva R, Jardim ACG, Siqueira WL. Coronavirus COVID-19 impacts to dentistry and potential salivary diagnosis. Clin Oral Investig 2020;24:1619-1621

27. Consolo U, Bellini P, Bencivenni D, Iani C, Checchi V. Epidemiological Aspects and Psychological Reactions to COVID-19 of Dental Practitioners in the Northern Italy Districts of Modena and Reggio Emilia. Int J Environ Res Public Health 2020;17:3459 doi: 10.3390/ijerph17103459.

28. Fallahi HR, Keyhan SO, Zandian D, Kim SG, Cheshmi B. Being a front-line dentist during the Covid-19 pandemic: a literature review. Maxillofac Plast and Reconstr Surg 2020;42:12 doi: 10.1186/s40902-020-00256-5.

29. Saitoh A, Sato K, Magara Y. Improving Hand Hygiene Adherence in Healthcare Workers Before Patient Contact: A Multimodal Intervention in Four Tertiary Care Hospitals in Japan. J Hosp Med 2020;15:262-267

30. NYS, Department of Health (2020) Interim Guidance for Cleaning and Disinfection of Public and Private Facilities for COVID-19: https://coronavirus.health.ny.gov/system/ files/documents/2020/03/cleaning_guidance_general_ building.pdf 